\title{
RESEARCH
}

Open Access

\section{Multidisciplinary recommendations for diagnosis and treatment of foot problems in people with rheumatoid arthritis}

Marloes Tenten-Diepenmaat ${ }^{1 *}$ (D, Marike van der Leeden ${ }^{1,2,3}$, Thea P. M. Vliet Vlieland ${ }^{4}$, Joost Dekker ${ }^{2,3}$ and on behalf of the RA Foot Expert Group

\begin{abstract}
Background: Foot problems in people with rheumatoid arthritis (RA) are highly prevalent and have a substantial impact on quality of life. Healthcare professionals from various professions can be involved in the management of these foot problems. There is currently no consensus on optimal management. Therefore, the aim of the present study was to develop multidisciplinary recommendations for the management of foot problems in people with RA in the Netherlands.

Methods: The recommendations were based on research evidence and consensus among experts, following published strategies for the development of practice recommendations. The expert group was composed of 2 patients and 22 experienced professionals (rheumatologists, rehabilitation physicians, orthopaedic surgeons, specialized nurses, podiatrists, orthopaedic shoe technicians, pedicurists, and researchers) in the Netherlands. For each developed recommendation i) the level of evidence was determined, and ii) the level of agreement (among the expert group) was set by an anonymous voting procedure using a numeric rating scale. The mean and range of the level of agreement for each recommendation was calculated. A recommendation was approved when $\geq 70 \%$ of the expert group voted an NRS-agreement $\geq 7$.
\end{abstract}

Results: In total, 41 recommendations were developed. Two recommendations concerned a framework for diagnosis and treatment. Thirty-nine recommendations on foot care were developed: seven on diagnosis (including check-ups of feet and shoes and diagnostic imaging), 27 on treatment (including corticosteroid injections, foot surgery, therapeutic shoes, foot orthoses, exercise therapy, toe-orthoses and toenail-braces, treatment of toenails and skin), four on communication, and one on organisation of RA-related footcare. All recommendations were approved by the expert group. The percentage score of NRS-agreement $\geq 7$ ranged from 80 to $100 \%$.

Conclusions: These are the first published multidisciplinary recommendations specific to the management of foot problems in people with RA. Multidisciplinary recommendations can provide guidance in timely referrals and access to adequate footcare. More research is needed to strengthen the evidence on diagnosis and treatment of RA-related foot problems. These national recommendations may be a first step towards developing international multidisciplinary recommendations for the management of foot problems in RA.

Keywords: Rheumatoid arthritis, Foot, Recommendations, Multidisciplinary

\footnotetext{
* Correspondence: m.tenten@reade.nl

${ }^{1}$ Amsterdam Rehabilitation Research Center | Reade, Amsterdam, the

Netherlands

Full list of author information is available at the end of the article
}

(c) The Author(s). 2018 Open Access This article is distributed under the terms of the Creative Commons Attribution 4.0 International License (http://creativecommons.org/licenses/by/4.0/), which permits unrestricted use, distribution, and reproduction in any medium, provided you give appropriate credit to the original author(s) and the source, provide a link to the Creative Commons license, and indicate if changes were made. The Creative Commons Public Domain Dedication waiver (http://creativecommons.org/publicdomain/zero/1.0/) applies to the data made available in this article, unless otherwise stated. 


\section{Background}

Approximately $90 \%$ of patients with rheumatoid arthritis (RA) experience foot problems, such as pain, swelling, and stiffness, during the course of the disease [1-4]. In a more advanced stage of RA, joint damage and foot deformities may occur [5]. In addition, dermatological abnormalities and reduced sensitivity are more frequent in people with RA compared with the healthy population [6]. Foot involvement in RA may result in an abnormal foot function, limitations in daily activities such as standing and walking, and a reduced quality of life $[7,8]$.

It seems important to start management of foot problems in an early disease stage to reduce pain and activity limitations, and to prevent deterioration of foot function [9]. The primary treatment of foot problems related to disease activity is systemic medication. In addition, local pharmacological treatment (corticosteroid injections), surgical treatment, or conservative treatment (such as foot orthoses, therapeutic shoes, removal of callosities) can be applied [10]. Apart from rheumatologists and orthopaedic surgeons, healthcare professionals from various professions can be involved. In the Netherlands there is a role for rehabilitation physicians, specialized nurses, podiatrists, orthopaedic shoe-technicians, and pedicurists in the management of RA-related foot problems [10]. A multidisciplinary approach is necessary in order to offer treatment with adequate content and timing for the individual patient $[9,11,12]$.

Despite the high prevalence of foot problems in RA, underuse of foot care seems apparent. In a specialized center for rheumatology and rehabilitation in the Netherlands only $40 \%$ of the people with RA received specific footcare (10), while in primary care foot problems appear to be treated even less. Among healthcare professionals there is often limited expertise in detecting and managing RA-related foot problems, as shown in a survey among podiatrists in New South Wales [13]. Similarly, among patients there is limited knowledge of the possibilities of, and access to, footcare [13, 14]. A survey among patients in the Netherlands showed that $94 \%$ of the patients reported insufficient knowledge about the content and accessibility of health care services [14].

Multidisciplinary recommendations provide guidance on timely referrals and access to adequate footcare. Previously published guidelines were recently critically appraised by Hennessy et al. [15]. In their work, 24 guidelines recommending management of RA-related foot problems were identified. Of these guidelines, only five (general) guidelines were of high quality and recommended for use without modifications. Moreover, only a small section of the guidelines (ranging from one sentence to one page) were foot-specific [15]. Only two published guidelines were foot and ankle specific, one of low [12] and one of high [11] quality [15]. Additionally, these guidelines are monodisciplinary (podiatry) $[11,12]$. The aim of the present study was to develop multidisciplinary recommendations and frameworks for the diagnosis and treatment of foot problems in people with RA.

\section{Methods}

Recommendations for management of RA-related foot problems were based on research evidence and consensus among experts (healthcare providers, patients, and researchers). The methodology for the development of the recommendations was based on published strategies for the development of practice recommendations $[16,17]$. The expert group was composed of patients (experienced with foot problems and related treatments) and experienced professionals (from leading expertise centres or nominated by professional bodies) of several professions involved in RA footcare in the Netherlands. The expert group included two patients, two rheumatologists, two rehabilitation physicians, three orthopaedic surgeons, four specialized nurses, two podiatrists, three orthopaedic shoe technicians, two pedicurists, and four researchers (the core members; MTD, MvdL, TPMVV and JD). Three expert group meetings took place between February 2015 and July 2016.

There were four phases in the development of the recommendations. A detailed description of the steps taken in the different phases, is given in Table 1 . In the first phase, definitive research questions and semi-definitive frameworks for diagnosis and treatment were developed based on: i) a preliminary literature search, ii) semi-structured interviews with four persons with RA, iii) a field consultation among 39 RA footcare professionals (medical doctors/allied healthcare professionals), iv) discussion within the core members, and v) discussion with the experts during the first expert group meeting.

In the second phase, draft recommendations were formulated (by the core members) based on relevant literature, to answer the research questions. Literature was searched in PubMed by MTD. Additional file 1 gives an overview of the search-details. The available (systematic) reviews on the subject of interest were used to develop the draft recommendations. When no (systematic) review was available, core publications (according to the expert group) or available guidelines were used.

In the third phase definitive recommendations and frameworks with a level of evidence were developed. The draft recommendations and semi-definitive frameworks were discussed with the experts during a second expert meeting and by email rounds. The draft recommendations and semi-definitive frameworks were refined into definitive recommendations and frameworks. For each final recommendation/framework, the level of 
Table 1 Development of the recommendations

Phase 1. Development of research-questions and semi-definitive frameworks for diagnosis and treatment

a Preliminary literature search in books, protocols and review articles

b Semi-structured interviews with 4 RA patients experienced with foot problems and related treatments

c Field consultation among 39 RA footcare professionals (medical doctors/allied healthcare professionals) by assessing a semistructured interview $(n=6)$ or by using a questionnaire during an expert meeting $(n=33)$. The overall question to be answered: "Which questions would you like to see answered by the recommendations? Regarding to your field of expertise (diagnostics and treatment) and in the context of a multidisciplinary approach"

d Draft research questions and draft frameworks (for diagnosis and treatment) were developed, by the core members of the expert group (MTD, MvdL, TPMW and JD), based on the results of point a-c.

e Discussion with the experts on the draft research questions and frameworks, during the first expert group meeting.

f Refining draft research questions and frameworks into definitive research questions and semi-definitive frameworks with the expert group, during the first expert group meeting.

Phase 2. Development of draft recommendations

g A search strategy was developed for each research question (see Additional file 1). Literature was searched in PubMed by MTD. The available (systematic) reviews on the subject of interest were used. When no (systematic) review were available, core publications (according to the expert group) were used.

h Draft recommendations were formulated (by the core members) based on the literature found at point $\mathrm{g}$.

Phase 3. Development of definitive recommendations and frameworks with a level of evidence

i Discussion with the experts on the draft recommendations and semi-definitive frameworks, during the second expert group meeting and 2 email-rounds.

j Refining draft recommendations and semi-definitive frameworks into definitive recommendations and frameworks, during the second expert group meeting and 2 email-rounds.

k Determining the level of evidence for each definitive recommendation/framework according to "Evidence-Based Guideline Development" of the Quality Institute for Public Healthcare in The Netherlands. Five levels of evidence were distinguished (ranging from 1 to $4 \mathrm{~b}$ ). When a recommendation was based on a review or guideline, the level of evidence reported in the review/guideline was used. If the level of evidence was not reported, the original sources were retrieved (individual studies/ expert opinion)

Phase 4. Determining the level of agreement for the definitive recommendations and frameworks

I During the third expert group meeting an anonymous voting procedure was followed. For each recommendation/framework a numeric rating scale for agreement (NRS-agreement) from 0 (total disagreement) to 10 (total agreement) was assessed.

$m$ The mean and range of the level of agreement for each recommendation was calculated. A recommendation was approved when $\geq 70 \%$ of the expert group voted an NRS-agreement $\geq 7$.

evidence was determined. The methodological quality was determined according to the "Evidence-Based Guideline Development" of the Quality Institute for Public Healthcare in The Netherlands, as shown in
Table 2 [18]. Five levels of evidence were distinguished (ranging from 1 to $4 \mathrm{~b}$ ), as shown in Table 3 . When a recommendation was based on a review or guideline, the level of evidence reported in the review/guideline was used. If the level of evidence was not reported, the original sources were retrieved (individual studies/ expert opinion).

In the fourth phase, the level of agreement for each recommendation/framework was set by an anonymous voting procedure during the third expert meeting. A numeric rating scale for agreement (NRS-agreement) from 0 (total disagreement) to 10 (total agreement) was used. The mean and range of the level of agreement for each recommendation was calculated. A recommendation was approved when $\geq 70 \%$ of the expert group voted a NRS-agreement $\geq 7$ [19].

\section{Results}

Fifteen research questions were developed during phase 1. Two (out of 15) research questions concerned the quality of the developed frameworks for diagnosis and treatment. These frameworks and answers to the related research questions were based on expert opinion. The answers of 13 (out of 15) research questions were based on both literature and expert opinion. Additional file 1 shows an overview of the developed research questions and the answering methods. The developed frameworks were reflected in two recommendations. Furthermore, 39 care-related recommendations were developed: seven on diagnosis, 27 on treatment, four on communication and one on organisation of footcare. All recommendations were approved. Tables 4, 5, 6, 7, 8, 9 give an overview of the developed recommendations with references to the literature used, the level of evidence, and the level of agreement. The percentage score of NRS-agreement $\geq 7$ ranged from 80 to $100 \%$.

\section{Frameworks for diagnosis and treatment}

A framework for diagnosis and a framework for treatment were developed by using the terminology of the International Classification of Functioning, Disability and Health (ICF) of the World Health Organization [20]. (Table 4) provides an overview of the developed recommendations on the frameworks for diagnosis and treatment.

The framework for diagnosis, as shown in Fig. 1, provides an overview of the different objectives in diagnosis of foot problems in RA and the corresponding instruments. Different objectives in diagnosis can be distinguished: i) detection of RA-related foot conditions; ii) medical diagnosis of RA; iii) (work-) diagnosis of foot function, dermatological factors, neuro-vascular factors, limitations in daily activities and restrictions in participation, external factors, and personal factors; and iv) monitoring of the progression of foot conditions/problems. 
Table 2 EBRO classification of methodological quality of individual studies [18]

A1 Systematic review of at least two independent studies of A2-level
A2 Randomized double-blind controlled clinical trial of good quality
and of sufficient size
B Controlled trial but not with all the characteristics as mentioned
under A2
C Non-controlled studies
D Expert opinion

For the Dutch situation, the role of the healthcare professions involved was described per objectives in diagnosis, as shown in Additional file 2.

The framework for treatment, as shown in Fig. 2, provides an overview of the treatment options for RA-related foot problems. The primary objectives in treatment are i) treatment of RA, ii) treatment of abnormal foot function, and iii) treatment of dermatological problems. In addition, treatment of neuro-vascular abnormalities should be considered. For the Dutch situation, the role of the involved healthcare professions was described per objectives in treatment, as shown in Additional file 3.

\section{Diagnosis}

\section{Check-ups of feet and shoes}

Regular check-ups (for example annually) of the feet of people with RA are of great importance in detecting disease activity in an early stage. Especially because the most frequently used instrument to detect disease activity (with a 28 joint count [21]) excludes examination of the feet. Regular check-ups are also important in people with RA in remission, since pain and swelling of MTP joints are present in a substantial part of this patient group [22-24]. Long-term synovitis of foot joints can lead to joint damage and deformity [22]. Furthermore, check-ups of over-the-counter shoes worn by the patient are indicated. Malalignment of the feet is very common in people with RA and can cause pain during weight-bearing activities and difficulties with shoe-fitting. Inadequate shoe fit can lead to high local

Table 3 Level of evidence

\begin{tabular}{ll}
\hline & Evidence is based on \\
\hline 1 & $\begin{array}{l}\text { Research of level A1 or at least } 2 \text { independently conducted studies } \\
\text { of level A2 }\end{array}$ \\
2 & $\begin{array}{l}1 \text { study of level A2 or at least } 2 \text { independently conducted studies of } \\
\text { level B }\end{array}$ \\
3 & 1 study of level B or C \\
$4 a$ & Expert opinion described in the literature \\
$4 \mathrm{~b}$ & Opinion of the expert group \\
\hline
\end{tabular}

pressure and subsequent pain. The required fit and function of the shoes varies per person with RA. (Table 5) provides an overview of the developed recommendations on check-ups of feet and shoes.

\section{Diagnostic imaging}

Diagnostic imaging can be performed in addition to assessment of patient history and physical examination. Assessment of X-rays is an essential part of diagnosis of foot involvement (erosions and deformities of forefoot joints) by the rheumatologist. Ultrasonography can optionally be applied to detect and monitor foot involvement (synovitis in foot joints and inflammation of soft tissues). (Table 6) provides an overview of the developed recommendations on diagnostic imaging.

\section{Treatment}

\section{Medical treatment}

Medical treatment primarily consists of the prescription of systemic medication by the rheumatologist. In addition, local medication can be applied in foot joints and soft tissues by corticosteroid injections. Furthermore, foot surgery can be performed to reduce pain and improve/maintain independent mobility, especially when a conservative treatment (neither medication nor surgery) is not successful or indicated. (Table 7) provides an overview of the developed recommendations on medical treatment.

\section{Conservative treatment}

Conservative treatment can be prescribed in addition to medical treatment. Conservative treatment can include therapeutic shoes, custom-made foot orthoses, exercise therapy, custom-made silicone toe orthoses, toenail braces, and treatment of toenails and skin. (Table 8) provides an overview of the developed recommendations on conservative treatment.

Therapeutic shoes can be prescribed in patients with abnormal foot function, damage/deformity of foot joints, or malalignment of the feet. Therapeutic shoes can be ready-made or custom-made. Ready-made shoes are i) over-the-counter shoes with technical adaptation, or ii) serially-produced shoes with extra depth, support, incorporated inlays, and optional technical adaptations $[25,26]$. Custom-made shoes are developed for the individual patient based on specific measures and specifications, whereby a variety of technical adaptations can be incorporated $[25,26]$.

Custom-made foot orthoses can be prescribed to facilitate physical functioning by reducing pain and improving foot function [27-31]. In order to reduce pain and to improve foot function, the specific objectives of the foot orthoses can include i) normalising vertical plantar foot pressure, ii) reducing shear-forces acting on the feet, 
Table 4 Recommendations on the framework for diagnosis and the framework for treatment of RA-related foot problems

\begin{tabular}{lllll}
\hline & LoE & Ref & LoA \\
\hline $\begin{array}{l}\text { The "Framework for diagnosis of RA-related foot } \\
\text { problems" (Fig. 1) provides an overview of the } \\
\text { different objectives in detection, diagnosis, and }\end{array}$ & & n/a & 9.2 (7-10) \\
monitoring of foot problems in people with RA, & & & \\
as well as the corresponding instruments. & & & \\
$\begin{array}{l}\text { The "Framework for treatment of RA-related foot } \\
\text { problems" (Fig. 2) provides an overview of the } \\
\text { potential treatment per diagnostic outcome. }\end{array}$ & n/a & 9.1 (6-10) \\
\hline
\end{tabular}

LOE Level of Evidence for the recommendations: (1) research of level A1 or at least 2 independently conducted studies of level A2, (2) 1 study of level A2 or at least 2 independently conducted studies of level B, (3) 1 study of level B or $C$, (4a) expert opinion described in the literature, (4b) opinion of the expert group. Ref. references, LoA Level of Agreement for the recommendations, Numeric Rating Scale from 0 (total disagreement) to 10 (total agreement) reported as mean (range). $n / a$ not applicable

iii) correcting malalignment in feet with adequate joint mobility, and iv) supporting feet when correction is not indicated [27, 29, 32, 33].

Exercise therapy, in general, can be applied in people with RA to improve social participation and functioning in daily life [34]. Exercise therapy specific to the foot and ankle can be prescribed for the treatment of pain, muscle weakness, imbalance, and limited joint mobility [33].

Table 5 Recommendations on check-ups of feet and shoes

\begin{tabular}{|c|c|c|c|}
\hline & LoE & Ref & LoA \\
\hline $\begin{array}{l}\text { Rheumatologists and nurses specialised } \\
\text { in rheumatology should perform regular } \\
\text { feet check-ups. These check-ups should } \\
\text { include, at least, patient history of foot } \\
\text { disease, foot inspection, and palpation } \\
\text { of foot joints for the detection of } \\
\text { swelling and pain. }\end{array}$ & $4 b$ & $n / a$ & $9.2(8-10)$ \\
\hline $\begin{array}{l}\text { Over-the-counter shoes should have, } \\
\text { at least, sufficient room in the toe box } \\
\text { and a stiff sole allowing a heel-to-toe } \\
\text { gait. *The following additional shoe } \\
\text { features may be important, depending } \\
\text { on the foot conditions and wishes } \\
\text { of the patient: i) light weight; ii) spacious, } \\
\text { adjustable, and easy to close in-step/heel } \\
\text { girth; iii) strong, raised, and padded heel } \\
\text { part; iv) inflection point at the MTP joints; } \\
\text { v) adequate length and width, measured } \\
\text { in standing position; vi) no seams on the } \\
\text { inside; vii) removable insoles so that } \\
\text { custom-made foot orthoses can be } \\
\text { placed in it.** }\end{array}$ & ${ }^{*} 3^{* *} 4 a$ & $\begin{array}{l}*[46]{ }^{* *} \\
{[32,33]}\end{array}$ & $9.3(7-10)$ \\
\hline
\end{tabular}

LOE Level of Evidence for the recommendations: (1) research of level A1 or at least 2 independently conducted studies of level A2, (2) 1 study of level A2 or at least 2 independently conducted studies of level B, (3) 1 study of level B or $C_{1}(4 a)$ expert opinion described in the literature, (4b) opinion of the expert group. Ref. references. LoA Level of Agreement for the recommendations: Numeric Rating Scale from 0 (total disagreement) to 10 (total agreement) reported as mean (range). $n / a$ not applicable. ${ }^{*}$ refers to the first part of the recommendation with corresponding level of agreement and references. ** refers to the second part of the recommendation with corresponding level of agreement and references
Custom-made silicone toe orthoses can be applied to i) correct a non-rigid abnormal toe-position and ii) to reduce local high pressure at the toes [35].

Toenail braces (made of surgical steel wire, titanium wire, or plastics, and attached to the nail with gel, acrylic, or composite) can be applied to improve the shape of the toenail by lifting the medial or lateral side [36].

Treatment of toenails and skin can include treatment of i) nail fungus, ii) hyperkeratotic lesions, and iii) (pre-)ulcers or infections. Treatment of nail fungus consists of i) debridement of all hypertrophic and dystrophic nail-plates, ii) medication (oral or local), iii) patient-advice regarding the cause and treatment of the toenail fungus $[32,36]$. In people with RA, prominent metatarsal heads are subject to high pressure and excessive shear forces during gait. These stresses stimulate the skin (stratum corneum) to produce hyperkeratotic lesions [32]. This can cause pain, corns, and wounds/ulcers $[32,36]$. Scalpel or mechanical trimming techniques can be used to treat excessive hyperkeratotic lesions [36].

\section{Communication and organisation of RA-related footcare}

Adequate communication between the patient and healthcare professional about the cause of foot problems, available treatment options, and anticipated outcomes are of great importance during the course of treatment. Understanding and involvement of the patient in determining the treatment strategy are important for adherence to the treatment and coping with the disease. Furthermore, specific advice on shoes and preventive and curative RA-related footcare is important for adequate self-management.

Healthcare professionals from various professions can be involved in the diagnosis and treatment of RA-related foot disease. The involvement of various professions depends on the severity of the foot problems, the work-field and expertise of the attending healthcare professionals, the organisation of footcare in the geographical area, and the preferences of the patient. Good communication and shared decision-making between the involved professionals is of great importance for adequate, multidisciplinary footcare in people with RA. (Table 9) provides an overview of the developed recommendations on communication and organisation of RA-related footcare.

\section{Discussion}

These are the first published multidisciplinary recommendations specific to the management of foot problems in RA. The recommendations are based on the best available evidence and the opinions of experts with varying specialities and of patients. Forty-one recommendations (eight on diagnosis, 32 on treatment (of which four on communication) and one on organisation of footcare) 
Table 6 Recommendations on diagnostic imaging

\begin{tabular}{|c|c|c|c|}
\hline & LoE & Ref & LoA \\
\hline $\begin{array}{l}\text { For the detection of joint damage in the feet, a non-weight-bearing X-ray in anterior-posterior } \\
\text { (AP) direction is the preferred method. }\end{array}$ & $4 b$ & $\mathrm{n} / \mathrm{a}$ & $8.6(0-10)$ \\
\hline $\begin{array}{l}\text { For the detection of joint deformity and malalignment of the foot, a weight-bearing X-ray in } \\
\text { anterior-posterior (AP) and lateral directions is the preferred method. }\end{array}$ & $4 b$ & $\mathrm{n} / \mathrm{a}$ & $9.6(7-10)$ \\
\hline Ultrasonography can be applied in the diagnosis of inflammation of joints* and soft tissue**. & 2 & $\begin{array}{l}*[47,48] \\
{ }^{*}[49,50]\end{array}$ & $9.4(7-10)$ \\
\hline When clinical examination is inconclusive in the diagnosis of inflammation of joi & $* 4 a * 4 b$ & $*[51]{ }^{* *} n / a$ & $9.2(8-10)$ \\
\hline
\end{tabular}
tissue, ultrasonography should be considered. *When ultrasonography is inconclusive, additional diagnostic imaging (MRI or CT scan) can be considered.**

LoE Level of Evidence for the recommendations: (1) research of level A1 or at least 2 independently conducted studies of level A2, (2) 1 study of level A2 or at least 2 independently conducted studies of level B, (3) 1 study of level B or C, (4a) expert opinion described in the literature, (4b) opinion of the expert group. Ref. references. LoA Level of Agreement for the recommendations: Numeric Rating Scale from 0 (total disagreement) to 10 (total agreement) reported as mean (range). $n / a$ not applicable. * refers to the first part of the recommendation with corresponding level of agreement and references. ** refers to the second part of the recommendation with corresponding level of agreement and references

were developed and approved by the expert group. In a recently published critical appraisal on clinical practice guidelines for the foot and ankle in RA, domains for foot and ankle management were identified [15]. The domains included in the previously published guidelines were multidisciplinary team care, access to foot healthcare, foot health assessment/review, orthoses/insoles/ splints, therapeutic footwear, and other footcare treatments (patient education; corticosteroid injections; and treatment of hyperkeratotic lesions, wounds, and fungal infections) [15]. The present study covers these domains with up-to-date recommendations, based on literature and expert opinion. In addition, recommendations were developed on communication, foot surgery, exercise therapy, and the application of toenail-braces and provisional therapy (e.g. felt padding or taping) with clearly described contra-indications. The present recommendations address the total range of diagnostics and treatment options as applied in The Netherlands. Treatment of excessive callosities is recommended, although

Table 7 Recommendations on medical treatment

\begin{tabular}{|c|c|c|c|}
\hline & LoE & Ref & LOA \\
\hline $\begin{array}{l}\text { Corticosteroid injections can be applied in joints and soft tissue of the foot in the treatment } \\
\text { of local arthritis and synovitis. }{ }^{*} \text { Corticosteroid injections may also be applied in the treatment } \\
\text { of tendinitis and pain.** }\end{array}$ & ${ }^{*} 2 * * a / b$ & $*[52][53] * *[32,54,55]$ & $8.7(7-10)$ \\
\hline $\begin{array}{l}\text { A corticosteroid injection conducted by ultrasonography (if available) is preferred, because this } \\
\text { may result in a more accurate determination of the location of the injection. }\end{array}$ & $4 b$ & $\mathrm{n} / \mathrm{a}$ & $9.4(7-10)$ \\
\hline $\begin{array}{l}\text { Early in the treatment process, consultation by an orthopaedic surgeon should be considered. } \\
\text { Surgical intervention should be considered when the following foot conditions do not respond } \\
\text { to conservative therapy: i) persistent pain and stiffness, ii) }>6 \text { months of synovitis in foot and } \\
\text { ankle joints, iii) tenosynovitis or tendon ruptures, iv) malalignment of the foot (e.g., hammer toes) } \\
\text { causing mobility limitations and pain or problems finding adequate shoes, v) returning } \\
\text { callosity/clavus, vi) wounds/(pre)ulcers, and vii) osteomyelitis/septic arthritis. }\end{array}$ & $4 a / b$ & {$[27,32,56]$} & $9.1(6-10)$ \\
\hline $\begin{array}{l}\text { Resection arthroplasty of the MTP joints can be applied to improve joint mobility and to reduce } \\
\text { pain, forefoot plantar pressure, and problems finding well-fitting shoes.* In severe malalignments } \\
\text { of the toes or damage to the MTP joints, resection arthroplasty is preferred. Without severe } \\
\text { malalignments/damage, a MTP joint-preserving surgical technique can be considered.** }\end{array}$ & ${ }^{*} 3{ }^{* *} 4 a$ & $*[57] *[56]$ & $8.9(6-10)$ \\
\hline $\begin{array}{l}\text { An arthrodesis of the MTP1 joint can be performed to reduce pain and improve the weight-bearing } \\
\text { capacity of the forefoot. }\end{array}$ & 3 & [37] & $9.1(7-10)$ \\
\hline $\begin{array}{l}\text { When surgical treatment of the hindfoot is necessary, arthrodesis of the subtalar joint is preferred. } \\
\text { For flat feet, an additional arthrodesis of the calcaneocuboid joint and talonavicular joint should be } \\
\text { considered (triple arthrodesis). }\end{array}$ & $4 a$ & [39] & $8.9(6-10)$ \\
\hline In the treatment of severe pain and damage of the tibiotalar joint, an arthrodesis of the tibiotalar & $*^{*}{ }^{* *} 4 \mathrm{~b}$ & $*[58]{ }^{* *} \mathrm{n} / \mathrm{a}$ & $9.0(7-10)$ \\
\hline
\end{tabular}
joint or an ankle prosthesis can be applied.* An arthrodesis is preferred, provided that the Chopart-joint-line is intact and the status of other joints does not form a contraindication. An ankle prosthesis can be considered when preservation of mobility in the tibiotalar joint is important (according to the patient) and the preoperative status of the patient does not form a contra-indication.**

LoE Level of Evidence for the recommendations: (1) research of level A1 or at least 2 independently conducted studies of level A2, (2) 1 study of level A2 or at least 2 independently conducted studies of level B, (3) 1 study of level B or C, (4a) expert opinion described in the literature, (4b) opinion of the expert group. Ref. references, LoA Level of Agreement for the recommendations: Numeric Rating Scale from 0 (total disagreement) to 10 (total agreement) reported as mean (range). $n / a$ not applicable. * refers to the first part of the recommendation with corresponding level of agreement and references. ** refers to the second part of the recommendation with corresponding level of agreement and references 
Table 8 Recommendations on conservative treatment

\begin{tabular}{|c|c|c|c|}
\hline & LoE & Ref & LoA \\
\hline $\begin{array}{l}\text { Technical adaptations to over-the-counter shoes can reduce pain and } \\
\text { improve physical functioning.* These adaptations can be prescribed in } \\
\text { patients with abnormal foot function, foot joint damage/deformity, or } \\
\text { malalignment of the feet, provided that the feet fit in over-the-counter shoes.** }\end{array}$ & $* 3 * * 4 b$ & ${ }^{*}[59]{ }^{* *} n / a$ & $9.3(8-10$ \\
\hline Ready-made therapeutic shoes with extra depth, support, incorporated inlays, & $* 3 * 4 b$ & $*[46,60-64]]^{* *} \mathrm{n} / \mathrm{a}$ & $9.3(7-10$ \\
\hline
\end{tabular}
and optional technical adaptation can reduce forefoot plantar pressure and foot pain and improve gait characteristics, physical functioning, and health-related quality of life.* These ready-made shoes can be prescribed in patients with i) abnormal foot function, foot joint damage/deformity, or malalignment of the feet, and ii) feet that do not fit in over-the-counter shoes, but for whom custom-made shoes are not indicated.**

Custom-made therapeutic shoes can reduce pain and improve physical functioning.* These custom-made shoes can be prescribed in patients with i) abnormal foot function, foot joint damage/deformity, or malalignment of the feet, and ii) feet that do not fit in over-the-counter shoes or ready-made therapeutic shoes.**

Custom-made therapeutic shoes should be worn all day, after a habituation period.

Foot orthoses are recommended in patients with abnormal foot function, when adequate over-the-counter shoes are insufficient in reducing foot symptoms.

Foot orthoses in adequate shoes can reduce forefoot plantar pressure and pain.

The function of foot orthoses should be assessed in relation to the patient's footwear, due to the interaction between the two.

Rigid foot orthoses are recommended in feet with correctable malalignment, to control the position of the feet during weight-bearing.

Total contact foot orthoses are recommended in feet with uncorrectable malalignment or fragile skin. The material used for the production of total contact foot orthoses depends on the required characteristics of the foot orthoses.

General exercise therapy is recommended according to the Dutch KNGF Guideline for Physical Therapy in Patients with Rheumatoid Arthritis.

Exercise therapy specific to the foot and ankle can include i) strengthening exercises for the intrinsic foot muscles and $M$. tibialis posterior; ii) active stretch exercises for the plantar fascia, achilles-tendon, and peroneal muscles; and iii) active exercises to improve joint mobility.

A silicone toe orthosis can be used in the treatment of malalignment of toes and secondary pain or high pressure.

In the prescription of a silicone toe orthosis, the following factors should be considered: i) a sensibility disorder or peripheral artery disease; ii) a skin defect on the foot of interest; and iii) sufficient room in the shoe for wearing the toe orthosis.

A toenail brace can be used in the treatment of an ingrowing or ingrown toenail. ^

In the prescription of a toenail brace, the following factors should be considered: i) a sensibility disorder or peripheral artery disease; ii) a skin defect, inflammation, or onycholysis on the toe of interest; and iii) the use of biologicals.

When a fungal nail or mycosis of the skin is detected, treatment should be started to prevent ulcers and secondary bacterial infections.

Pressure and shearing forces should be normalised in feet with hyperkeratotic lesions. For normalisation of pressure and shearing forces, i) an individual shoe- and sock advice can be given; or ii) foot orthoses, silicone toe orthosis, technical adaptations to over-the-counter shoes, ready- or custom-made therapeutic shoes, or a provisional therapy (e.g., felt padding or taping) can be prescribed.

Excessive hyperkeratotic lesions should be treated. During the treatment the following factors should be considered: i) a sensibility disorder or peripheral artery disease, and ii) fragile skin, plantar bursa, and prominent metatarsal heads on the foot of interest.

When an (pre-)ulcer or infection is detected, the treating physician should be consulted.

$* 3 * 4 b$

* [25] **n/a

$9.5(8-10)$

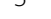

.

4a/b

[25]

$8.5(0-10)$

$4 a$

$4 a / b$

1

$4 a$

3

$4 a / b$

2

4a/b

$4 a / b$

4a/b

$4 a / b$

$[32,36]$

$9.1(7-10)$

4a/b

[32]
$9.0(2-10)$

$9.4(7-10)$

$9.0(6-10)$

$8.8(7-10)$

$9.2(7-10)$

$9.3(8-10)$

$8.8(5-10)$

$9.3(7-10)$

$9.0(7-10)$

$9.0(6-10)$ In wound-care, a provisional therapy (e.g., felt padding) can be applied to reduce pressure. When material with an adhesive layer is used, fragile skin should be taken into consideration. 
Table 9 Recommendations on communication and organisation of RA-related footcare

\begin{tabular}{|c|c|c|c|}
\hline & LoE & Ref & LoA \\
\hline $\begin{array}{l}\text { Regular consultation and shared decision-making between the patient and healthcare professional } \\
\text { should be included in RA-related footcare and should be customised to the individual patient. }\end{array}$ & $4 \mathrm{~b}$ & $\mathrm{n} / \mathrm{a}$ & $8.8(5-10)$ \\
\hline $\begin{array}{l}\text { Individual shoe-advice to people with RA with foot problems is essential and should include } \\
\text { information on fit, cosmetics, function, durability and correct use of the shoes. }\end{array}$ & $4 a / b$ & {$[32,33,35]$} & $9.4(8-10)$ \\
\hline $\begin{array}{l}\text { Footcare in patients with RA should include patient education.* Patient education may consist } \\
\text { of preventive and curative care.** }\end{array}$ & $*^{*}{ }^{* * 4 b}$ & $*[68]{ }^{* *} n / a$ & $9.6(7-10)$ \\
\hline Patient education on preventive care for RA-related foot problems should contain information about & $4 a$ & {$[11,32,33,35]$} & $9.3(8-10)$ \\
\hline
\end{tabular}
i) the cause and course of RA and RA-related foot disease; ii) recognition of infection and increased disease activity (systemic and local); iii) footcare and hygiene; iv) recognition and use of adequate footwear (for indoors and outdoors); v) timely consultation by a healthcare professional in the case of foot infection, symptoms of increased disease activity, pain, problems finding adequate footwear, and skin and nail conditions; and vi) the healthcare professional who may be consulted for a specific indication.

Patient education on curative care for RA-related foot problems should contain information about i) the treatment strategy (short and long term); ii) the importance of treatment adherence and compliance; iii) the expected treatment results according to pain, physical functioning, activities, and participation; iv) the possible adverse events; and v) costs and reimbursement of the treatment.

A multidisciplinary approach in management of RA-related foot problems is recommended. The diagnosis and treatment of RA-related foot disease consists of different aspects, which require the expertise of several disciplines.

LoE Level of Evidence for the recommendations: (1) research of level A1 or at least 2 independently conducted studies of level A2, (2) 1 study of level A2 or at least 2 independently conducted studies of level B, (3) 1 study of level B or C, (4a) expert opinion described in the literature, (4b) opinion of the expert group. Ref.references. LoA Level of Agreement for the recommendations: Numeric Rating Scale from 0 (total disagreement) to 10 (total agreement) reported as mean (range). $n / a$ not applicable. * refers to the first part of the recommendation with corresponding level of agreement and references. ** refers to the second part of the recommendation with corresponding level of agreement and references

it is in contrast to the limited available evidence. One RCT showed no benefit of callus debridement over a sham procedure in terms of pain reduction, while sharp debridement may introduce potential risks [37]. Another RCT showed no-long term effect of sharp scalpel debridement on painful forefoot plantar callosities [38]. Despite this evidence, the expert group had the opinion that hyperkeratotic lesions can be treated, provided that the pre-defined contra-indications are taken into account. Moreover, for the Dutch situation, the role of the healthcare professions involved was described per objective in diagnosis and treatment. It should be noted that the present recommendations are aimed at managing RA-related foot problems in the Netherlands. Since the content, (expertise of) involved disciplines, and organisation of RA-related footcare may vary per country, this may hamper the generalizability of the frameworks and recommendations to other countries.

The level of evidence of the developed recommendations varies from 1 (highest) to 4 (lowest). Overall, most of the developed recommendations were based on expert opinion, as there is a lack of research evidence. Only a few number of the topics addressed in the recommendations were subject of investigation in previously published high-quality research. Evidence, based on randomised controlled trials' ("RCT") between-group differences, was found for the application of corticosteroid injections (in finger joints, based on a single RCT), foot orthoses (for treatment of pain and high forefoot pressure, based on multiple RCTs), ready-made therapeutic shoes (for treatment of high plantar pressure, based on a single RCT), patient education (not foot specific), and exercise therapy (not foot specific). A lower level of evidence (based on uncontrolled studies) was found for the application of ultrasonography, foot surgery, therapeutic shoes, silicone toe-orthoses, and toenail braces. Our findings clearly indicate that there are gaps in scientific literature on the management of foot problems in people with RA. More research is needed to strengthen the evidence on diagnosis and treatment of RA-related foot problems. Multiple areas with a lack of evidence were identified. The following topics for future research on diagnosis are indicated: i) diagnostic research on the psychometric properties, timing and frequency of ultrasonography for the detection of erosions and inflammation in the feet, and ii) the value of (yearly) check-up of the feet for the prevention or delay in progression of RA-related foot problems. For treatment the following topics for future research are identified: i) a definitive, high-quality RCT to investigate the effectiveness of corticosteroid injections in the foot, ii) RCTs on the effectiveness of different types of (fore-)foot surgery, therapeutic shoes, treatment of nails and hyperkeratotic lesions, and the comparative effectiveness of foot orthoses, and iii) development and evaluation of a foot-specific patient education program.

A multidisciplinary approach in the diagnosis and treatment of RA-related foot problems is recommended, as supported by several previously published guidelines $[11,12,39-41]$. Based on the opinion of the expert group, 


\begin{tabular}{|c|c|c|}
\hline \multirow[t]{3}{*}{ DOMAIN } & DIAGNOSTICAL QUESTION & DIAGNOSTICAL INSTRUMENT \\
\hline & $\begin{array}{l}\text { foot problems or suspicion of RA? } \\
\text { diagnosed RA and (history with) foot problems? }\end{array}$ & patient history \\
\hline & $1 \times$ yes $2 \times$ no: no further diagnostics & \\
\hline \multirow[t]{2}{*}{ rheumatoid arthritis (RA) } & damage of foot joints & $\mathrm{X}$-ray (non-weight bearing) \\
\hline & inflammation of foot joints / soft tissue & $\begin{array}{l}\text { palpation } \\
\quad \text { swelling and pain } \\
\text { ultrasonography } \\
\end{array}$ \\
\hline \multirow[t]{2}{*}{$\begin{array}{l}\text { alignment and function } \\
\text { of the feet }\end{array}$} & malalignment & inspection \\
\hline & abnormalities in function & $\begin{array}{l}\text { assessment of function } \\
\text { muscle strength/tone } \\
\text { joint mobility } \\
\text { inspection } \\
\text { gait characteristics } \\
\text { plantar pressure measurements } \\
\end{array}$ \\
\hline dermatological factors & $\begin{array}{r}\text { abnormalities in skin and nails } \\
\text { high risk for foot wounds? }\end{array}$ & $\begin{array}{l}\text { patient history } \\
\text { question on medication } \\
\text { inspection }\end{array}$ \\
\hline \multirow[t]{2}{*}{ neuro-vascular factors } & sensibility disorder & sensitivity tests \\
\hline & vascular disorder & $\begin{array}{l}\text { inspection } \\
\text { skin and color } \\
\text { presence of varicosities or edema } \\
\text { palpation } \\
\text { skin temperature } \\
\text { pulsations of tibialis posterior artery } \\
\text { and dorsalis pedis artery } \\
\text { assessment with doppler } \\
\text { assessment of Ankle Arm Index } \\
\end{array}$ \\
\hline \multirow[t]{2}{*}{ activity and participation } & $\begin{array}{l}\text { foot-related impairments in daily activities } \\
\text { e.g., walking }\end{array}$ & patient history \\
\hline & $\begin{array}{l}\text { foot-related restrictions in participation } \\
\text { e.g., social participation and work }\end{array}$ & patient history \\
\hline \multirow[t]{2}{*}{ external factors } & fit of over-the counter-shoes & \begin{tabular}{|l} 
patient history \\
inspection \\
$\quad$ fit and function of shoes
\end{tabular} \\
\hline & $\begin{array}{l}\text { fit of assistive device } \\
\text { foot orthoses } \\
\text { ready-made or custom-made therapeutic shoes } \\
\text { silicone toe orthosis }\end{array}$ & $\begin{array}{l}\text { patient history } \\
\text { inspection } \\
\text { fit and function of assistive device }\end{array}$ \\
\hline \multirow[t]{2}{*}{ personal factors } & perceptions on the foot symptoms & patient history \\
\hline & expectations of the treatment & patient history \\
\hline
\end{tabular}

Fig. 1 Framework for diagnosis of RA-related foot disease 


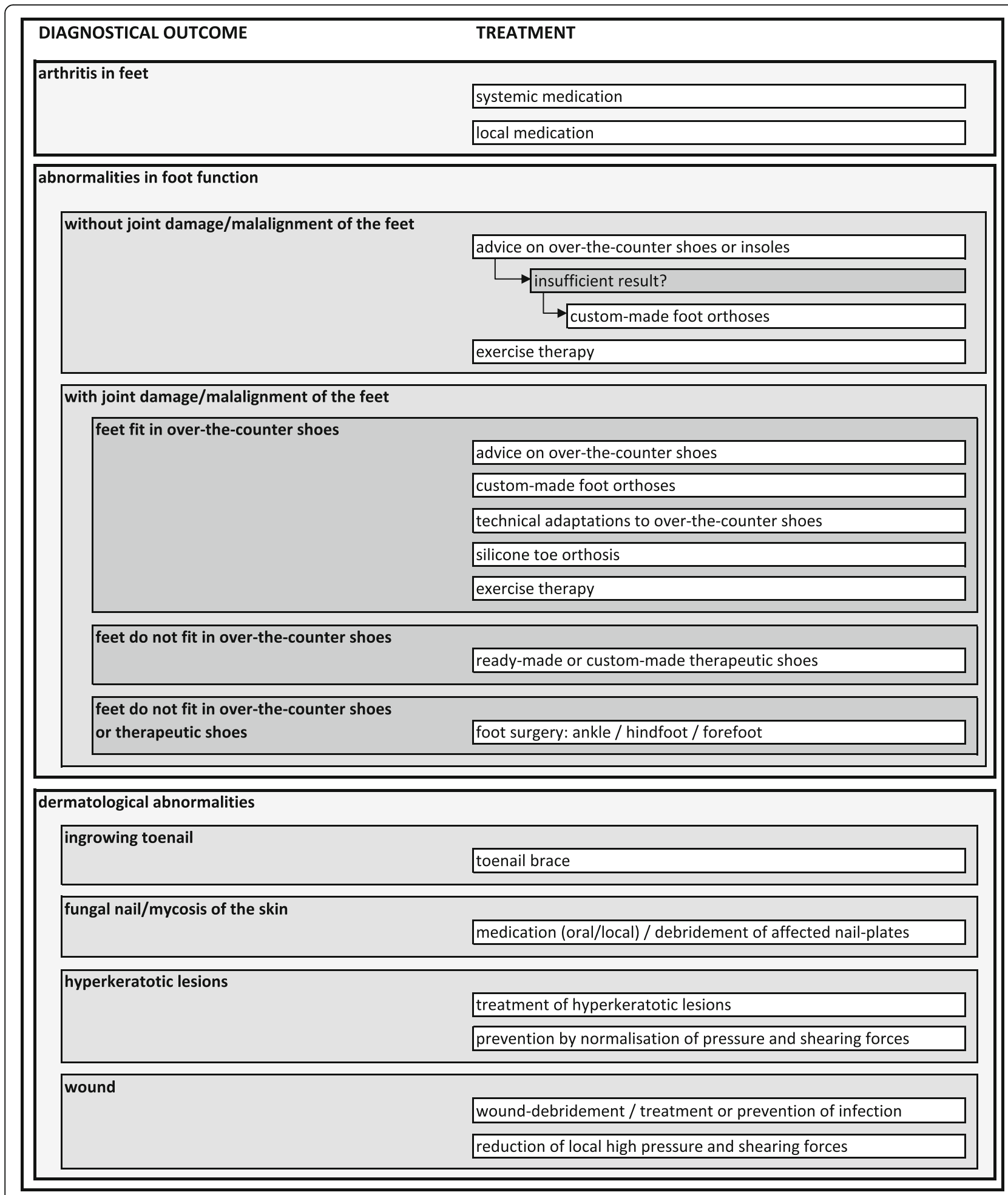

Fig. 2 Framework for treatment of RA-related foot problems

a multidisciplinary approach should consist of i) regular check-ups of the feet (for example annually) by a rheumatologist or a specialized nurse and, if indicated, ii) referral to another discipline (rehabilitation physician, orthopaedic surgeon, podiatrist, orthopaedic shoe-technician, pedicurist, or physical therapist). Referral should be considered when foot problems exist after reaching clinical remission [22-24, 42], when 
patients with increased disease states have mechanical foot impairments $[5,8]$, or when patients do not respond to or are ineligible for biological therapy and therefore continue to have active foot involvement [9]. Furthermore, adequate communication between the healthcare professionals involved and the patient (including shared decision-making and patient education) should be part of the treatment [43]. For example, in the prescription of therapeutic footwear communication and shared decision are of importance, especially to promote compliance of wearing them [44]. Adequate communication could be supported by a combined consultation with the professionals involved. In addition, (web-based) educational material may be helpful in patient education and could be developed within a network of specialised healthcare professionals or by patient organisations [45]. The healthcare professionals involved in, the access to, and the timing and content of management of foot problems may vary per country/geographical region. Therefore, developing and maintaining a network of specialised healthcare professionals, as well as developing a footcare pathway for diagnosis and treatment within this network are important steps in supporting multidisciplinary management $[11,12]$.

These are the first published multidisciplinary recommendations specific to the diagnosis and treatment of foot problems in people with RA. Expert opinions of several involved healthcare professions and patients (experienced in living with RA-related foot problems) were included in the recommendations. These national recommendations may be a first step towards developing international multidisciplinary recommendations for the management of foot problems in RA. The developed recommendations aim to contribute to i) uniformity in diagnosis, treatment, and guidance of people with RA-related foot problems; and ii) improved communication between, on the one hand, patient and treating healthcare professionals, and, on the other hand, between the healthcare professionals themselves. In future recommendations, the inclusion of more healthcare professions, such as general practitioners and physical therapists, who also have a role in RA foot management, could be considered. The development of the recommendations gave insight into the limited research evidence available on management of foot problems in RA. The gaps in literature could be topics for future research. Overall, more attention to RA-related foot problems in research is justified, as these are highly prevalent and have a substantial impact on patient quality of life.

\section{Conclusions}

These are the first published multidisciplinary recommendations specific to the management of foot problems in people with RA. Multidisciplinary recommendations can provide guidance in timely referrals and access to adequate footcare. More research is needed to strengthen the evidence on diagnosis and treatment of RA-related foot problems. These national recommendations may be a first step towards developing international multidisciplinary recommendations for the management of foot problems in RA.

\section{Additional files}

Additional file 1: Overview of the developed research questions and the used answering methods. (DOCX $51 \mathrm{~kb}$ )

Additional file 2: Framework for diagnosis with an overview of the role of the involved healthcare professions in the Netherlands. (DOCX $816 \mathrm{~kb}$ )

Additional file 3: Framework for treatment with an overview of the role of the involved healthcare professions in the Netherlands. (DOCX $774 \mathrm{~kb}$ )

\section{Abbreviations}

ICF: International Classification of Functioning, Disability and Health; NRSagreement: Numeric rating scale for agreement; RA: Rheumatoid arthritis

\section{Acknowledgements}

Group authorship is attributed to the RA Foot Expert Group. All members of this group had a substantial contribution to the development of the recommendations.

The members of the RA Foot Expert Group are:

- Prof. Dr. Dirkjan van Schaardenburg, Amsterdam Rheumatology and Immunology Center, Reade and Academic Medical Center, Amsterdam, The Netherlands

- Dr. Wiepke Drossaers-Bakker, Medisch Spectrum Twente, Department of Rheumatology, Enschede, The Netherlands

- Bianca Lourens, Slingeland Hospital, Department of Rheumatology, Doetinchem, The Netherlands

- Els van Buuren, Meander Medisch Center, Department of Rheumatology, Amersfoort, The Netherlands

- Rianne van Berkel, Elisabeth-TweeSteden Hospital, Department of Rheumatology, Tilburg, The Netherlands

- Patricia Smith-van der Meijde, Noordwest Ziekenhuisgroep, Department of Rheumatology, Alkmaar, The Netherlands

- Dr. Leo Roorda, Amsterdam Rehabilitation Research Center | Reade, Amsterdam, the Netherlands

- Dr. Antal Sanders, Dorati Consultancy for Feet and Health, Katwijk, The Netherlands

- Dr. Huub van der Heide, Leiden University Medical Center, Department of Orthopaedics, Leiden, the Netherlands

- Kirsten Veenstra, Sint Maartenskliniek, Department of Orthopaedics, Woerden, The Netherlands

- Sabine van Vliet-Koppert, Leiden University Medical Center, Department of Orthopaedics, Leiden, the Netherlands

- Elleke Huijbrechts, Fontys University of Applied Sciences, Department of Allied Health Professions, Eindhoven, The Netherlands

- Michel Boerrigter, Feet Center Wender, Enschede, The Netherlands

- Rob Verwaard, Wittepoel Pedorthic Footwear, Rotterdam, The Netherlands

- Arthur Arets, Leuk Orthopedics, Amersfoort, The Netherlands

- Willem Seves, Walking Center for Sports and Orthopedics, Nijverdal, The Netherlands

- Toos Mennen, Medical Pedicurist Center Weert, Weert, The Netherlands

- Maya Ribbink, Studio Pedicare, Apeldoorn, The Netherlands

- Bertha Maat, Patient Partners, The Netherlands

- Wijnanda Hoogland, Patient Partners, The Netherlands 


\section{Funding}

We would like to thank 1) the Dutch Association of Podiatrists 'NVVP', 2) the Dutch industry organization for orthopedic shoe technicians 'NVOS Orthobanda', and 3) the Dutch industry organization for pedicurists 'ProVoet' for financially supporting this project. None of these organizations had a role in developing the study design, collection, analysis, interpretation or manuscript writing.

\section{Availability of data and materials}

The datasets used and/or analysed during the current study are available from the corresponding author on reasonable request.

\section{Authors' contributions}

The authors MTD, MvdL, TPMW and JD had a substantial contribution to study conception and design. MTD and MvdL performed data acquisition. All authors (MTD, MvdL, TPMW, JD and RA Foot Expert Group) had a substantial contribution to analysis and interpretation of data, and drafting the article or revising it critically for important intellectual content. All authors read and approved the final manuscript.

\section{Ethics approval and consent to participate}

Not applicable.

\section{Consent for publication}

Not applicable.

\section{Competing interests}

The first author (MTD) declares to have a podiatry practice and to have a cooperation with a company in producing therapeutic shoes. Both companies may potentially benefit from, or be harmed by, publication of the results of the study. The co-authors declare that they have no competing interests.

\section{Publisher's Note}

Springer Nature remains neutral with regard to jurisdictional claims in published maps and institutional affiliations.

\section{Author details}

${ }^{1}$ Amsterdam Rehabilitation Research Center | Reade, Amsterdam, the Netherlands. ${ }^{2}$ Department of Rehabilitation Medicine, VU University Medical Center, Amsterdam, the Netherlands. ${ }^{3}$ Amsterdam Public Health research institute, VU University Medical Center, Amsterdam, the Netherlands. ${ }^{4}$ Department of Orthopaedics, Rehabilitation and Physical Therapy, Leiden University Medical Center, Leiden, the Netherlands.

Received: 12 December 2017 Accepted: 7 June 2018

\section{Published online: 04 July 2018}

\section{References}

1. Otter SJ, Lucas K, Springett K, Moore A, Davies K, Cheek L, Young A, WalkerBone K. Foot pain in rheumatoid arthritis prevalence, risk factors and management: an epidemiological study. Clin Rheumatol. 2010;29:255-71.

2. Rome K, Gow PJ, Dalbeth N, Chapman JM. Clinical audit of foot problems in patients with rheumatoid arthritis treated at counties Manukau District health board, Auckland, New Zealand. J Foot Ankle Res. 2009;2:16.

3. Grondal L, Tengstrand B, Nordmark B, Wretenberg P, Stark A. The foot: still the most important reason for walking incapacity in rheumatoid arthritis: distribution of symptomatic joints in 1,000 RA patients. Acta Orthop. 2008; 79:257-61.

4. Michelson J, Easley M, Wigley FM, Hellmann D. Foot and ankle problems in rheumatoid arthritis. Foot Ankle Int. 1994;15:608-13.

5. van der Leeden M, Steultjens MP, Ursum J, Dahmen R, Roorda LD, Schaardenburg DV, Dekker J. Prevalence and course of forefoot impairments and walking disability in the first eight years of rheumatoid arthritis. Arthritis Rheum. 2008:59:1596-602.

6. Woodburn J, Helliwell PS. Relation between heel position and the distribution of forefoot plantar pressures and skin callosities in rheumatoid arthritis. Ann Rheum Dis. 1996;55:806-10.

7. Wickman AM, Pinzur MS, Kadanoff $R$, Juknelis D. Health-related quality of life for patients with rheumatoid arthritis foot involvement. Foot Ankle Int. 2004;25:19-26.
8. van der Leeden M, Steultjens M, Dekker JH, Prins AP, Dekker J. The relationship of disease duration to foot function, pain and disability in rheumatoid arthritis patients with foot complaints. Clin Exp Rheumatol. 2007:25:275-80.

9. Woodburn J, Hennessy K, Steultjens MP, McInnes IB, Turner DE. Looking through the 'window of opportunity': is there a new paradigm of podiatry care on the horizon in early rheumatoid arthritis? J Foot Ankle Res. 2010;3:8.

10. Marsman AF, Dahmen R, Roorda LD, van Schaardenburg D, Dekker J, Britsemmer K, Knol DL, van der Leeden M. Foot-related health care use in patients with rheumatoid arthritis in an outpatient secondary care center for rheumatology and rehabilitation in the Netherlands: a cohort study with a maximum of fifteen years of followup. Arthritis Care Res (Hoboken). 2013; 65:220-6.

11. Standards of Care for people with Musculoskeletal Foot Health Problems. Podiatry Rheumatic Care Association; 2008.

12. Williams AE, Davies S, Graham A, Dagg A, Longrigg K, Lyons C, Bowen C. Guidelines for the Management of the Foot Health Problems Associated with rheumatoid arthritis. Musculoskeletal Care. 2011;9:86-92.

13. Hendry GJ, Gibson KA, Pile K, Taylor L, du Toit V, Burns J, Rome K. Provision of foot health services for people with rheumatoid arthritis in new South Wales: a web-based survey of local podiatrists. J Foot Ankle Res. 2013;6:35.

14. Meesters J, de Boer I, van den Berg M, Fiocco M, Vliet Vlieland T. Unmet information needs about the delivery of rheumatology health care services: a survey among patients with rheumatoid arthritis. Patient Educ Couns. 2011;85:299-303.

15. Hennessy K, Woodburn J, Steultjens M. Clinical practice guidelines for the foot and ankle in rheumatoid arthritis: a critical appraisal. J Foot Ankle Res. 2016;9:31.

16. van der Heijde D, Aletaha D, Carmona L, Edwards CJ, Kvien TK, Kouloumas M, Machado P, Oliver S, de Wit M, Dougados M. 2014 update of the EULAR standardised operating procedures for EULAR-endorsed recommendations. Ann Rheum Dis. 2015;74:8-13.

17. Dougados M, Betteridge N, Burmester GR, Euller-Ziegler L, Guillemin F, Hirvonen J, Lloyd J, Ozen S, Da Silva JA, Emery P, et al. EULAR standardised operating procedures for the elaboration, evaluation, dissemination, and implementation of recommendations endorsed by the EULAR standing committees. Ann Rheum Dis. 2004;63:1172-6.

18. Burgers JS, van Everdingen JJ. Evidence-based guideline development in the Netherlands: the EBRO platform. Ned Tijdschr Geneeskd. 2004;148:2057-9.

19. Uson J, Loza E, Moller I, Acebes C, Andreu JL, Batlle E, Bueno A, Collado P, Fernandez-Gallardo JM, Gonzalez C, et al. Recommendations for the use of ultrasound and magnetic resonance in patients with Spondyloarthritis, including psoriatic arthritis, and patients with juvenile idiopathic arthritis. Reumatol Clin. 2016;

20. International Classification of Functioning, Disability and Health [http:// www.who.int/classifications/icf/en/].

21. Prevoo ML, van 't Hof MA, Kuper $H H$, van Leeuwen $M A$, van de Putte $L B$, van Riel PL. Modified disease activity scores that include twenty-eight-joint counts. Development and validation in a prospective longitudinal study of patients with rheumatoid arthritis. Arthritis Rheum. 1995;38:44-8.

22. van der Leeden M, Steultjens MP, van Schaardenburg D, Dekker J. Forefoot disease activity in rheumatoid arthritis patients in remission: results of a cohort study. Arthritis Res Ther. 2010;12:R3.

23. Bakker MF, Jacobs JW, Kruize AA, van der Veen MJ, van Booma-Frankfort C, Vreugdenhil SA, Bijlsma JW, Lafeber FP, Welsing PM. Misclassification of disease activity when assessing individual patients with early rheumatoid arthritis using disease activity indices that do not include joints of feet. Ann Rheum Dis. 2012;71:830-5.

24. Wechalekar MD, Lester S, Hill CL, Lee A, Rischmueller M, Smith MD, Walker JG, Proudman SM. Active foot synovitis in patients with rheumatoid arthritis: unstable remission status, radiographic progression, and worse functional outcomes in patients with foot synovitis in apparent remission. Arthritis Care Res (Hoboken). 2016;68:1616-23.

25. Dahmen R, Buijsmann S, Siemonsma PC, Boers M, Lankhorst GJ, Roorda LD. Use and effects of custom-made therapeutic footwear on lowerextremity-related pain and activity limitations in patients with rheumatoid arthritis: a prospective observational study of a cohort. J Rehabil Med. 2014:46:561-7.

26. Erkenningsschema branchespecifieke eisen orthopedische schoentechnische bedrijven, versie 22 december 2015 [https://www.semh. info/CMSDATA/Afbeeldingen/files/OSB\%20schema\%204.pdf]. 
27. Brooks F, Hariharan K. The rheumatoid forefoot. Curr. Rev. Muscoskelet. Med. 2013;6:320-7.

28. Hennessy K, Woodburn J, Steultjens MP. Custom foot orthoses for rheumatoid arthritis: a systematic review. Arthritis Care Res (Hoboken). 2012; 64:311-20.

29. Riskowski J, Dufour AB, Hannan MT. Arthritis, foot pain and shoe wear: current musculoskeletal research on feet. Curr Opin Rheumatol. 2011;23: $148-55$.

30. Conceicao CS, Gomes Neto M, Mendes SM, Sa KN, Baptista AF. Systematic review and meta-analysis of effects of foot orthoses on pain and disability in rheumatoid arthritis patients. Disabil Rehabil. 2015;37:1209-13.

31. Grifka JK. Shoes and insoles for patients with rheumatoid foot disease. Clin Orthop Relat Res. 1997:18-25.

32. Guidelines for the management of foot health for people with rheumatoid arthritis. North west podiatry services. Clinical effectiveness group rheumatology:; October 2010.

33. Shrader JA. Nonsurgical management of the foot and ankle affected by rheumatoid arthritis. J Orthop Sports Phys Ther. 1999;29:703-17.

34. KNGF Richtlijn Reumatoide Artritis. Nederlands Tijdschrift voor Fysiotherapie; Jaargang 118, nummer 5, 2008.

35. Forestier R, André-Vert J, Guillez P, Coudeyre E, Lefevre-Colau M-M, Combe B, Mayoux-Benhamou M-A. Non-drug treatment (excluding surgery) in rheumatoid arthritis: clinical practice guidelines. Joint Bone Spine. 2009;76: 691-8.

36. Richtlijn behandeling van voeten van personen met een reumatische aandoening. ProVoet.; 2010.

37. Davys HJ, Turner DE, Helliwell PS, Conaghan PG, Emery P, Woodburn J. Debridement of plantar callosities in rheumatoid arthritis: a randomized controlled trial. Rheumatology. 2004;44:207-10.

38. Siddle HJ, Redmond AC, Waxman R, Dagg AR, Alcacer-Pitarch B, Wilkins RA, Helliwell PS. Debridement of painful forefoot plantar callosities in rheumatoid arthritis: the CARROT randomised controlled trial. Clin Rheumatol. 2012;32:567-74.

39. Luqmani R, Hennell S, Estrach C, Basher D, Birrell F, Bosworth A, Burke F, Callaghan C, Candal-Couto J, Fokke C, et al. British Society for Rheumatology and British health professionals in rheumatology guideline for the management of rheumatoid arthritis (after the first 2 years). Rheumatology (Oxford). 2009:48:436-9.

40. Clinical guideline for the diagnosis and management of early rheumatoid arthritis The Royal Australian College of General Practitioners.; August 2009.

41. Management of early rheumatoid arthritis. A national clinical guideline. Scottish intercollegiate guidelines network; February 2011.

42. Landewe $R$, van der Heijde $D$, van der Linden S, Boers M. Twenty-eight-joint counts invalidate the DAS28 remission definition owing to the omission of the lower extremity joints: a comparison with the original DAS remission. Ann Rheum Dis. 2006;65:637-41.

43. Graham AS, Stephenson J, Williams AE. A survey of people with foot problems related to rheumatoid arthritis and their educational needs. J Foot Ankle Res. 2017:10:12.

44. Williams AE, Nester CJ, Ravey MI. Rheumatoid arthritis patients' experiences of wearing therapeutic footwear - a qualitative investigation. BMC Musculoskelet Disord. 2007;8:104.

45. Graham AS, Williams AE. Foot health education provision for people with rheumatoid arthritis-an online survey of UK podiatrists' perceptions. J Foot Ankle Res. 2016;9:13.

46. Cho NS, Hwang JH, Chang HJ, Koh EM, Park HS. Randomized controlled trial for clinical effects of varying types of insoles combined with specialized shoes in patients with rheumatoid arthritis of the foot. Clin Rehabil. 2009;23: $512-21$.

47. Joshua F, Lassere M, Bruyn GA, Szkudlarek M, Naredo E, Schmidt WA, Balint $P$, Filippucci $E$, Backhaus $M$, lagnocco $A$, et al. Summary findings of a systematic review of the ultrasound assessment of synovitis. J Rheumatol. 2007:34:839-47.

48. Szkudlarek M, Terslev L, Wakefield RJ, Backhaus M, Balint PV, Bruyn GAW, Filippucci E, Gandjbakhch F, lagnocco A, Mandl P, et al. Summary findings of a systematic literature review of the ultrasound assessment of bone erosions in rheumatoid arthritis. J Rheumatol. 2015;43:12-21.

49. Koski JM. Ultrasound detection of plantar bursitis of the forefoot in patients with early rheumatoid arthritis. J Rheumatol. 1998;25:229-30.

50. Koski JM. Detection of plantar tenosynovitis of the forefoot by ultrasound in patients with early arthritis. Scand J Rheumatol. 1995;24:312-3.
51. Combe B, Landewe R, Lukas C, Bolosiu HD, Breedveld F, Dougados M, Emery P, Ferraccioli G, Hazes JMW, Klareskog L, et al. EULAR recommendations for the management of early arthritis: report of a task force of the European standing Committee for International Clinical Studies Including Therapeutics (ESCISIT). Ann Rheum Dis. 2006;66:34-45.

52. Haugeberg G, Morton S, Emery P, Conaghan PG. Effect of intra-articular corticosteroid injections and inflammation on periarticular and generalised bone loss in early rheumatoid arthritis. Ann Rheum Dis. 2011;70:184-7.

53. Hetland ML, Ostergaard M, Ejbjerg B, Jacobsen S, Stengaard-Pedersen K, Junker P, Lottenburger T, Hansen I, Andersen LS, Tarp U, et al. Short- and long-term efficacy of intra-articular injections with betamethasone as part of a treat-to-target strategy in early rheumatoid arthritis: impact of joint area, repeated injections, MRl findings, anti-CCP, IgM-RF and CRP. Ann Rheum Dis. 2012;71:851-6.

54. Balint GP, Korda J, Hangody L, Balint PV. Regional musculoskeletal conditions: foot and ankle disorders. Best Pract Res Clin Rheumatol. 2003;17: 87-111.

55. Hayes DW Jr, Gilbertson EK, Mandracchia VJ, Dolphin TF. Tendon pathology in the foot. The use of corticosteroid injection therapy. Clin Podiatr Med Surg. 2000;17:723-35.

56. Louwerens JWK, Schrier JCM. Rheumatoid forefoot deformity: pathophysiology, evaluation and operative treatment options. Int Orthop. 2013;37:1719-29.

57. Farrow SJ, Kingsley GH, Scott DL. Interventions for foot disease in rheumatoid arthritis: a systematic review. Arthritis Rheum. 2005;53:593-602.

58. Richtlijn Diagnostiek en behandeling van reumatoide artritis. Nederlandse Vereniging voor Reumatologie.; 2009.

59. Bagherzadeh Cham M, Ghasemi MS, Forogh B, Sanjari MA, Zabihi Yeganeh M, Eshraghi A. Effect of rocker shoes on pain, disability and activity limitation in patients with rheumatoid arthritis. Prosthetics Orthot Int. 2014; 38:310-5.

60. Chalmers AC, Busby C, Goyert J, Porter B, Schulzer M. Metatarsalgia and rheumatoid arthritis-a randomized, single blind, sequential trial comparing 2 types of foot orthoses and supportive shoes. J Rheumatol. 2000;27:1643-7.

61. Williams AE, Rome K, Nester CJ. A clinical trial of specialist footwear for patients with rheumatoid arthritis. Rheumatology. 2006;46:302-7.

62. Fransen M, Edmonds J. Off-the-shelf orthopedic footwear for people with rheumatoid arthritis. Arthritis Care Res (Hoboken). 1997;10:250-6.

63. Hennessy K, Burns J, Penkala S. Reducing plantar pressure in rheumatoid arthritis: a comparison of running versus off-the-shelf orthopaedic footwear. Clin Biomech (Bristol, Avon). 2007;22:917-23.

64. Moncur J, Ward JR. Heat-moldable shoes for Management of Forefoot Problems in rheumatoid arthritis. Arthitis Care Res. 1990;3:222-6.

65. Maddali Bongi S, Del Rosso A, Mikhaylova S, Landi G, Ferretti B, Cavigli E, Baccini M, Matucci-Cerinic M. A comparison of two podiatric protocols for metatarsalgia in patients with rheumatoid arthritis and osteoarthritis. Clin Exp Rheumatol. 2014;32:855-63.

66. Eekhof JA, Van Wijk B, Knuistingh Neven A, van der Wouden JC: Interventions for ingrowing toenails. Cochrane Database Syst Rev 2012: Cd001541.

67. Khunger N, Kandhari R. Ingrown toenails. Indian J. Dermatol. Venereol. Leprol. 2012;78:279.

68. Zangi HA, Ndosi M, Adams J, Andersen L, Bode C, Boström C, van EijkHustings Y, Gossec L, Korandová J, Mendes G, et al. EULAR recommendations for patient education for people with inflammatory arthritis. Ann Rheum Dis. 2015;74:954-62.

69. Smyth CJ, Janson RW. Rheumatologic view of the rheumatoid foot. Clin Orthop Relat Res. 1997:7-17. 